\title{
The prevalence of pseudoexfoliation syndrome in Pakistan. Hospital based study
}

\author{
Rashad Qamar Rao ${ }^{\dagger 1}$, Tariq Mehmood Arain ${ }^{\dagger 1}$ and Muhammad Ali Ahad*2
}

Address: ${ }^{1}$ Department of Ophthalmology, Bahawalpur Victoria Hospital, Bahawalpur, Pakistan and ${ }^{2}$ Department of Ophthalmology, South Wing St Thomas' Hospital, London SE1 7EH, UK

Email: Rashad Qamar Rao - drrashadqr@yahoo.com; Tariq Mehmood Arain - drtmapak@yahoo.com; Muhammad Ali Ahad* - ahad.muhammad@gmail.com

* Corresponding author †Equal contributors

Published: 22 June 2006

BMC Ophthalmology 2006, 6:27 doi:10.1/86/|47|-24|5-6-27
Received: 02 March 2006

Accepted: 22 June 2006

This article is available from: http://www.biomedcentral.com/I47I-24I5/6/27

(c) 2006 Rao et al; licensee BioMed Central Ltd.

This is an Open Access article distributed under the terms of the Creative Commons Attribution License (http://creativecommons.org/licenses/by/2.0), which permits unrestricted use, distribution, and reproduction in any medium, provided the original work is properly cited.

\begin{abstract}
Background: Pseudoexfoliation syndrome (PXS) is the most common identifiable cause of secondary glaucoma, the prevalence of which varies considerably among different ethnicities. The aim of this study was to assess the prevalence of pseudoexfoliation syndrome in Pakistan.

Methods: A prospective study conducted in the period from January 2003 to June 2004 in a teaching hospital serving a population of about 7.6 million. 1860 patients aged 45 or above attending the general ophthalmic clinics were recruited for this study. A detailed evaluation including ophthalmic and general history, slit lamp biomicroscopy, intraocular pressure measurement, gonioscopy and dilated eye examination was performed on all patients.

Results: $120(6.45 \%)$ subjects were found to have PXS with a male to female ratio of I.5:I. All I 20 (100\%) cases were bilateral and $48(40 \%)$ patients had high intraocular pressure.

Conclusion: To the best of our knowledge, this is the first study conducted in a Pakistani population to determine the prevalence of PXS. The prevalence rate of $6.45 \%$ is similar to other studies conducted in south Asia, however all cases were bilateral and quite a high percentage of patients had high intra-ocular pressure.
\end{abstract}

\section{Background}

Pseudoexfoliation syndrome (PXS) is characterized by the deposition of a distinctive fibrillar material in the anterior segment of the eye and was first described in 1917 by Lindberg [1]. It is frequently associated with open angle glaucoma, known as pseudoexfoliation glaucoma, which is the most common identifiable form of secondary open angle glaucoma worldwide [2]. Despite extensive research, the exact chemical nature of the fibrillar material is unknown. It is believed to be secreted multifocally in the iris pigment epithelium, the ciliary epithelium, and the peripheral anterior lens epithelium [3]. The material moves into the aqueous humor and is carried to the trabecular meshwork, following the normal flow. Obstruction of the trabecular meshwork by this fibrillar material and pigment causes elevation of the intraocular pressure (IOP) leading to glaucoma [4].

PXS is now suspected to be a systemic disorder and has been associated preliminarily with stroke, systemic hypertension, and myocardial infarction [5]. In fact pseudoexfoliative like material has been found in lungs, skin, liver, heart, kidney, gallbladder, blood vessels, extra ocular muscles and meninges [6]. 
PXS is rarely seen before the age of 50, and its prevalence increases markedly with age [7]. Although it occurs in virtually every area of the world, a considerable racial variation exists. In the Framingham study, prevalence of PXS was found to be $1.8 \%$ [8]. In another study of subjects over 60 years in various ethnicities, prevalence rates ranging from $0 \%$ in Greenland Eskimos to 21\% in Icelanders were noted [9]. In northern/western European countries including England, Germany, and Norway prevalence of $4.0 \%, 4.7 \%$, and $6.3 \%$ have been reported respectively [10].

Although epidemiological studies of PXS have been done in South Asia $[11,12]$, but there is no data available on prevalence of PXS in Pakistan. This study was performed to determine the prevalence of PXS in Pakistan.

\section{Methods}

After approval from Hospital Ethics Committee, cross-sectional hospital based study was performed at Bahawalpur Victoria Hospital, (BVH) Bahawalpur, Pakistan. BVH is a regional tertiary care centre and university hospital of Bahawalpur division that serves a population of 7,635,591 people. (PopulationCensus Organization 1998-census, Government of Pakistan) All the patients who were 45 years of age or older presenting to eye out patient department from January 2003 to June 2004 were asked to enrol for this study. After informed consent the patients underwent complete ophthalmic evaluation. This included complete ophthalmic and general history, best corrected visual acuity, slit lamp examination, applanation tonometry and gonioscopy. The patients were then dilated and slit lamp examination of the lens and fundus was carried out. The patients who were found to have narrow or occludable angles on gonioscopy were first offered laser iridotomy treatment. The rest of the evaluation was then deferred to a later date. An angle was considered occludable if the pigmented trabecular meshwork was not visible in $180 \mathrm{o}$ or more of the angle. For IOP measurement, only the higher IOP between the two eyes was considered. Any IOP of more than $22 \mathrm{~mm} \mathrm{Hg}$ was considered as high and only if the pressure was again high after 10 minutes of wait and tested by a second examiner on a different slit lamp. The criterion used to diagnose PXS was the presence of pseudoexfoliation material on one or more anterior segment structures. Since the presence of pseudoexfoliative material on lens is the most consistent and prominent feature of PXS, so to prevent under estimation of the prevalence, all subjects who were psuedophakic or aphakic in any eye were excluded from the study. Also noted were demographic details, reason of attendance and presence of any systemic disease. Since the aim of the study was prevalence of PXS in a given population so no attempt was made to determine the prevalence or incidence of glaucoma in PXS patients.

Statistical analysis was performed using Statistical Package for Social Sciences (SPSS version 12.0, Chicago IL). Chi square test was used to compare discrete variables and Mann Whitney test was used to compare ordinal data.

\section{Results}

1860 patients were recruited for the study. There were 1040 males and 820 female with a male female ratio of 1.27:1. Demographic details and the reason of attendance to the eye clinic are shown in Table 1 . The stratification of age is shown in Table 2.

120 patients were found to be having PXS with an overall prevalence of $6.45 \%$. The salient clinical features of the

Table I: Demographic details and reason of attendance to the eye clinic

\begin{tabular}{lcc}
\hline & All Patients $n=(I 860)$ & Patients with PXS N $=(I 20)$ \\
\hline Age in years & $45-87(63.6)$ & $5 I-84(72.2)$ \\
Male to Female ratio & $1.2-1$ & $1.5-1$ \\
Mean Vision & $6 / 18$ & $6 / 12$ \\
Prevalence of diabetes & $10.2 \%$ & $10.8 \%$ \\
Prevalence of high blood pressure & $13.4 \%$ & $16.6 \%$ \\
Reason of Attendance & & $52.5 \%$ \\
Cataract & $32.3 \%$ & $8.3 \%$ \\
Ocular surface/lid disorders & $23.7 \%$ & $15.0 \%$ \\
Age related macular degeneration & $11.3 \%$ & $5.0 \%$ \\
Diabetic retinopathy & $8.6 \%$ & $12.5 \%$ \\
Glaucoma & $8.2 \%$ & $0.0 \%$ \\
Uveitis & $3.0 \%$ & $5.0 \%$ \\
Retinal vascular diseases & $3.0 \%$ & $0.8 \%$ \\
Neurophthalmological Problems & $2.9 \%$ & $0.0 \%$ \\
Hereditery Retinal diseases & $1.7 \%$ & $0.8 \%$ \\
History of Infectious corneal ulcers & $1.3 \%$ & $0.0 \%$ \\
Others & $4.1 \%$ &
\end{tabular}


Table 2: Age distribution of studied population

\begin{tabular}{lcc}
\hline Age range & No. of subjects & Percentage \\
\hline $45-59$ years & 714 & $38.40 \%$ \\
$60-69$ years & 456 & $24.50 \%$ \\
70 and above & 690 & $37.10 \%$ \\
Total & 1860 & $100 \%$
\end{tabular}

patients with PXS are shown in Table 3. All cases were bilateral though asymmetrical. The mean age of patients with PXS was 72.2 years, which was significantly higher compared to 63.6 in whole examined population ( $\mathrm{p}<$ $0.0001)$

There were 72 males and 48 females with a male to female ratio of $1.5: 1$. The prevalence of PXS was $6.92 \%$ in males and $5.8 \%$ in females and this difference was not significant. The prevalence of PXS increased with the increasing age as shown in Table 4.

As shown in table $4,75 \%$ of the patients with PXS were 70 years old or above. The prevalence was $2.6 \%$ in patients less than 70 years of age, which increased to $13.04 \%$ in patients 70 years old or older. $(p=0.001)$. High IOP (more than 22) was noted in 48 patients $(40 \%)$. It was also noted that prevalence of high IOP increased with increasing age. The mean age of patient with PXS and high IOP $(\mathrm{n}=48)$ was 74.2 years compared to 71 years in patients with normal IOP $(\mathrm{n}=72) p=0.02$. Occludable angles were seen in 5 patients $(4.1 \%)$ with PXS compared to 40 patients $(2.29 \%)$ with out PXS. Although the occludable angles were more common in patients with PXS but the difference was not statistically significant and this difference could also be attributed to the age which was significantly higher in PXS group.

\section{Discussion}

The reported prevalence rate of PXS syndrome in different populations shows extensive variations, $0 \%$ in Eskimos [9], $1.8 \%$ in the United States [8], 5-25\% in the Scandinavian countries [9], and 38\% in Navajo Indians [13].
This variation is combination of true differences due to racial difference, the age and sex distribution of the population group examined, the criteria used to define examined populations that is, persons over a certain age, patients taken from eye clinics, patients with cataracts, and glaucoma patients. The prevalence of PXS increases progressively among the following groups: 1 ) the general population; 2) persons over age 50;3) ocular hypertensives; 4) glaucoma patients; 5) glaucoma patients admitted to the hospital.

This study is first study of its kind from Pakistan. Our examined population was recruited from the eye clinic and we found the prevalence to be $6.45 \%$. This is quite similar to $7.4 \%$ in a similar hospital based study from India [14] and $6 \%$ in south Indian population based survey [15] and slightly lower than in neighboring Iran where the prevalence was found to be $9.6 \%$ [16]. These geographic distribution patterns may perhaps be explained either by regional gene pools or by environmental influences. However it should be noted that prevalence in our study was significantly higher from two large epidemiological studies from South India $[11,12]$ and it could be attributed to design of the study which was different in our study.

We did not notice any sex predilection; however the prevalence was slightly higher in males. As expected and reported in other studies $[17-19]$ the prevalence increased with increasing age reaching $13.04 \%$ in patients over 70 years of age.

Table 3: Clinical features of the patients with pseudoexfoliation syndrome

\begin{tabular}{lc}
\hline Clinical Features & $\mathrm{n}=(\mid 20)$ \\
\hline Pseudoexfoliation of lens & $118(98.3 \%)$ \\
Flakes on Iris margin & $98(81.7 \%)$ \\
Poor pupil dilation & $80(66.7 \%)$ \\
Iris abnormalities & $76(63.3 \%)$ \\
Flakes on trabecular meshwork & $68(56.7 \%)$ \\
High intraocular pressure & $48(40 \%)$ \\
Zonular weakness & $30(25.0 \%)$ \\
Bilateral disease & $120(100 \%)$ \\
Occludable angles & $5(4.1 \%)$
\end{tabular}


Table 4: Prevalence of pseudoexfoliation stratified according to age groups.

\begin{tabular}{lccc}
\hline Age range & Number & percentage \\
\hline $50-59$ & 5 & $4.2 \%$ & $0.70 \%$ \\
$60-69$ & 25 & $5.48 \%$ & $20.8 \%$ \\
$70 \&$ above & 90 & $75 \%$ & $13.04 \%$ \\
Total & 120 & $6.45 \%$ & $100 \%$
\end{tabular}

An unexpected finding was a high percentage (40\%) of the subjects with PXS had high intraocular pressure. Most of the studies have shown prevalence of high intraocular pressure with or without glaucoma to be in between $22 \%$ to $30 \%$ [20-22]. It is quite possible that this high rate in our study may be due do the design of study which was hospital based.

We also noted that the PXS was bilateral in $100 \%$ of the cases, which is not documented by any study, but as shown by Prince et al and Speakman et al, the disease is invariably bilateral pathologically $[23,24]$. In our study, 30 eyes of the total 240 eyes with PXS had flakes on the iris only. The presence of flakes on the iris can be missed easily particularly in light colored eyes, so either the darker color of the iris makes it easily recognizable or south Asian people truly have high prevalence of clinically bilateral PXS [15] could be the possible explanation.

\section{Conclusion}

In conclusion we found the prevalence of PXS to be $6.45 \%$ in a Pakistani population. This rate is similar to other studies conducted in south Asia, however all cases were bilateral and quite a high percentage of patients had high intra-ocular pressure.

\section{Abbreviations}

PXS: pseudoexfoliation

IOP: intra-ocular pressure

BVH: Bahawalpur Victoria Hospital

\section{Competing interests}

The author(s) declare that they have no competing interests.

\section{Authors' contributions}

RQR conceived of the study and carried out clinical examination and data collection. TMA participated in clinical examination and data collection. MAA designed the study, carried out statistical analysis and drafted the manuscript. All authors read and approved the final manuscript.

\section{References}

I. Lindberg JG: Kliniska undersokningar over depigmenteringen av pupillarranden och genomlysbarheten av iris vid fall av aldersstarr samt i normala ogon hos gamla personer. In [Clinical studies of depigmentation of the pupillary margin and transillumination of the iris in cases of senile cataract and also in normal eyes in the aged] [Thesis] Helsinki, Finland: Helsinki University; 1917.

2. Ritch R: Exfoliation syndrome: The most common identifiable cause of open-angle glaucoma. Trans Am Ophthalmol Soc 1994, 92:845-944.

3. Dickson DH, Ramsey MS: Symposium on pseudocapsular exfoliation and glaucoma. Fibrillopathia epitheliocapsularis: review of the nature and origin of pseudoexfoliative deposits. Trans Ophthalmol Soc U K 1979, 99(2):284-92.

4. Haydon PR: Pseudoexfoliation syndrome as a cause of chronic glaucoma. Klin Monatsbl Augenheilkd I986, I 89(4):293-30I.

5. Mitchell P, Wang JJ, Smith W: Association of pseudoexfoliation syndrome with increased vascular risk. Am J Ophthalmol 1997, 1 24(5):685-7.

6. Schlotzer-Schrehardt UM, Koca MR, Naumann GO, Volkholz H: Pseudoexfoliation syndrome. Ocular manifestation of a systemic disorder? Arch Ophthalmol 1992, I I 0(I 2): 1752-6.

7. Aasved $\mathrm{H}$ : Mass screening for fibrillopathia epitheliocapsularis, so-called senile exfoliation or pseudoexfoliation of the anterior lens capsule. Acta Ophthalmol (Copenh) 197I, 49(2):334-43.

8. Hiller R, Sperduto RD, Krueger DE: Pseudoexfoliation, intraocular pressure, and senile lens changes in a population based survey. Arch Ophthalmol 1982, 100:1080-2.

9. Forsius $\mathrm{H}$ : Prevalence of pseudoexfoliation of the lens in Finns, Lapps, Icelanders, Eskimos and Russians. Trans Ophthalmol Soc UK 1979, 99:296-298.

10. Aasved H: Prevalence of fibrillopathia epitheliocapsularis [pseudoexfoliation] and capsular glaucoma. Trans Ophthalmol Soc UK 1979, 99:293-295.

II. Thomas R, Nirmalan PK, Krishnaiah S: Pseudoexfoliation in southern India: the Andhra Pradesh Eye Disease Study. Invest Ophthalmol Vis Sci 2005, 46(4): I 70-6.

12. Arvind H, Raju P, Paul PG, Baskaran M, Ramesh SV, George RJ, McCarty C, Vijaya L: Pseudoexfoliation in South India. Br J Ophthalmol 2003, 87(II): 132I-3.

13. Faulkener HW: Pseudoexfoliation of the lens among Navajo Indians. Am J Ophthalmol 197I, 72:206-7.

14. Lamba PA, Giridhar A: Pseudoexfoliation syndrome [prevalence based on Random Survey Hospital data]. Indian J Ophthalmol 1984, 32:169-173.

15. Krishnadas R, Nirmalan PK, Ramakrishnan Thulasiraj RD, Katz J, Tielsch JM, Friedman DS, Robin AL: Pseudoexfoliation in a rural population of southern India: the Aravind Comprehensive Eye Survey. Am J Ophthalmol 2003, I3(6):830-7.

16. Nouri-Mahdavi K, Nosrat N, Sahebghalam R, Jahanmard M: Pseudoexfoliation syndrome in central Iran: a population-based survey. Acta Ophthalmol Scand 1999, 77(5):58I-4.

17. Cashwell LF Jr, Shields MB: Exfoliation syndrome: prevalence in a southeastern United States population. Arch Ophthalmol 1988, 106:335-36.

18. McCarthy CA, Taylor HR: Pseudoexfoliation syndrome in Australian adults. Am J Ophthalmol 2000, 129:629-33.

19. Mitchell P, Wang JJ, Hourihan F: The relationship between glaucoma and pseudoexfoliation: The Blue Mountains Eye Study. Arch Ophthalmol 1999, II7:1319-1324.

20. Kozart DM, Yanoff M: Intraocular pressure status in 100 consecutive patients with exfoliation syndrome. Ophthalmology 1982, 89:214-218. 
21. Kozobolis VP, Papatzanaki M, Vlachonikolis IG, Pallikaris IG, Tsambarlakis IG: Epidemiology of pseudoexfoliation in the island of Crete [Greece]. Acta Ophthalmol Scand 1997, 75:726-729.

22. Ringvold A, Blika S, Elsas T, Guldahl J, Brevik T, Hesstvedt P, Hoff K, Hoisen H, Kjorsvik S, Rossvold I: The middle-Norway eyescreening study. II. Prevalence of simple and capsular glaucoma. Acta Ophthalmol [Copenh] 199I, 69:273-280.

23. Prince AM, Streeten BW, Ritch R, Dark AJ, Sperling M: Preclinical diagnosis of pseudoexfoliation syndrome. Arch Ophthalmol 1987, 105:1076-1082.

24. Speakman JS, Ghosh M: The conjunctiva in senile lens exfoliation. Arch Ophthalmol 1976, 94: I757-I759.

\section{Pre-publication history}

The pre-publication history for this paper can be accessed here:

http://www.biomedcentral.com/1471-2415/6/27/prepub

Publish with Bio Med Central and every scientist can read your work free of charge

"BioMed Central will be the most significant development for disseminating the results of biomedical research in our lifetime. "

Sir Paul Nurse, Cancer Research UK

Your research papers will be:

- available free of charge to the entire biomedical community

- peer reviewed and published immediately upon acceptance

- cited in PubMed and archived on PubMed Central

- yours - you keep the copyright

Submit your manuscript here:

http://www.biomedcentral.com/info/publishing_adv.asp 